\title{
Children's reading skills: A comparison of traditional and computerized assessment
}

\author{
LARRY D. EVANS, RHONDA TANNEHILL, and SONIA MARTIN \\ University of Arkansas for Medical Sciences and Arkansas Children's Hospital \\ Little Rock, Arkansas
}

\begin{abstract}
Student's ability to read computer text was investigated by comparing reading performance on decoding and phonetics tests of the Woodcock-Johnson (Revised) Tests of Achievement, Forms A and B. Fifty-one students completed one form of the reading tests through the traditional administration method and a second form using computer administration. Initial form and administration order were counterbalanced. Coefficients of equivalence of .91 and .86 were obtained for traditional and computer administration methods of the two tests. The results are interpreted as indicating that computer-administered reading tests can assess the same domains as traditional measures, and that they may become increasingly important in the complete assessment of functional reading skills.
\end{abstract}

Computer applications for psychoeducational assessment have primarily consisted of scoring programs designed to convert raw scores to standard scores or percentiles, and of word-processing programs for writing reports. Other applications have included programs designed to analyze, integrate, store, or graph assessment data. These applications have focused on computer use after the psychological-assessment data have been gathered (Yokley, Coleman, \& Yates, 1990). Although such applications will remain important, the greatest potential for computers, and the direction of future expansion, will be computer use during assessment (Farrell, 1991). Computerized interest inventories and symptom checklists already exist for adults and adolescents with adequate reading skills. However, many problems exist in using computers for the assessment of children, including differences in reading skills, variability in computer proficiency, limitations of the two-dimensional computerscreen display, and variations in children's ability to relate computer presentation to actual situations or objects.

An initial area to study in using computers during pediatric psychological assessment, including psychoeducational assessment, is that of computer reading skills. The purpose of the following study was to compare children's reading abilities on the computer monitor with those on the traditional page display, and to examine how well psychologists can assess basic reading skills via computer administration. Acquisition of basic reading skills is the primary goal of early reading instruction, as well as a common deficiency for students with reading disabilities (Torgesen, 1986). Measuring children's reading skills on the computer will provide not only a general understanding of the manner in which text can be used on computers during any type of pediatric

Correspondence should be addressed to L. D. Evans, Department of Pediatrics, Dennis Developmental Center, 1612 Maryland Street, Little Rock, AR 72202. psychological assessment, but also information concerning the particular feasibility of computerized reading assessment.

\section{COMPUTERS AND READING}

Early studies comparing adult reading ability on printed page with that on computer display (e.g., Gould \& Grischkowsky, 1984; Wright \& Lickorish, 1983) generally found poorer reading accuracy on the computer. Later studies pointed to the text quality on the computer monitor as being responsible for the poorer accuracy (Gould, Alfaro, Barnes, \& Finn, 1987). Indeed, Muter and Maurutto (1991), using high-resolution computer monitors, found reading speed and comprehension comparable for computer and paper displays. Skimming speed, however, remained slower on the computer, indicating that other aspects of the computer interface, in addition to text quality, required improvement in order to make skimming, editing, and locating information as efficient on the computer as on the printed page (Haas \& Hayes, 1986; Mills \& Weldon, 1987).

\section{COMPUTERS AND STUDENT READING ABILITY}

Although software designed to supplement reading instruction and remediate reading deficits has been available for a number of years (Schaudt, 1987; Torgesen, 1986; Wepner, 1987), few studies have examined elementary and secondary students' ability to read information presented on computer displays. Gambrell, Bradley, and McLaughlin (1987) found that although third- and fifth-grade students comprehend information presented on printed page and computer monitor equally well, they report a preference for reading on the computer, but have more difficulty understanding the stories when presented on the computer. Kinzer, Sherwood, and Loofbourrow 
(1989) compared fifth graders' acquisition of science information from reading textbooks with that from computer simulation. Students receiving information from the computer demonstrated poorer acquisition, which was attributed to probable difficulties in reading from the computer monitor, as well as to illustrations that may have served as distractors.

\section{PURPOSE OF THE STUDY}

The reading level of printed material is based upon reading accuracy (i.e., the ease of decoding and pronouncing each word) and reading comprehension (i.e., the ease of understanding the words as they are organized within the material). Self-administered computer inventories and checklists for adults and adolescents require a specific reading level so that instructions and items can be accurately read and comprehended. Developing selfadministered or minimally assisted measures for children also requires attention to the reading level of the measures. Previous studies examining student reading ability on the computer have examined the comprehension, but not the accuracy, of reading. Although comprehension is the end goal of reading, reading comprehension is limited by reading accuracy. The primary purpose of the following study was to assess computer reading accuracy directly, through comparison with a standard printed-page assessment. Study results will provide information about the reading level necessary for children's instruction on the computer, as well as whether comprehension difficulties reported by previous studies stem from poor reading accuracy or result from other factors.

\section{METHOD}

\section{Subjects}

Fifty-one students consecutively referred to the Dennis Developmental Center for psychoeducational assessment were selected. All students agreed to participate. Student age ranged from 5 to 16 years, in keeping with the school-age population seen by the center. Selection criteria excluded students with sensory impairments or who had recently (within the past month) been administered the Woodcock-Johnson battery. However, to assess the range of reading ability, students with known reading problems or disorders were included.

\section{Instruments}

The Woodcock-Johnson Psychoeducational Battery-Revised Tests of Achievement (WJ-R; Woodcock \& Johnson, 1989, 1990) is a comprehensive measure of scholastic achievement for ages 2 -adult. Two of the 14 WJ-R tests assess basic reading skills: The LetterWord Identification Test measures knowledge of letter names and word pronunciation; and the Word Attack Test assesses a student's phonetic skills. Approximately $10 \mathrm{~min}$ are required to give each test. The WJ-R includes two forms (A and B). WJ-R standard scores have a mean of 100 and a standard deviation of 15 points.

The Sight Word Instrument for Teaching and Testing (SWIFTT; Evans, 1993) is a computer program designed to help teach and measure reading skills. SWIFTT presents individual letters and words on the computer screen to the student, and the user scores the student's reading accuracy on the computer.
The Computer Anxiety Rating Scale (CARS; Loyd \& Gressard, 1984 ) is a questionnaire for novice computer users and is designed to measure behavioral, cognitive, and affective components of computer anxiety. The scale is for adults, but has been studied with secondary and elementary populations. Items of the anxiety and liking subscales of the CARS were linguistically lowered, and the Likert-type response format modified, for the current study.

\section{Procedure}

Each student was administered both forms of the Letter-Word Identification and Word Attack Tests. One form was given in the traditional manner, using the test booklet, and the second form was given using SWIFTT. Order of the initial form (i.e., whether Form A or Form B was given first) and method of administration were randomly counterbalanced. The SWIFTT presented all words using a 12-point black font on a white background with a high-resolution monitor. The CARS was administered orally after the reading tests were completed.

\section{Analysis}

WJ-R scoring accuracy was verified using the WJ-R computerscoring program. Summary statistics were calculated to describe background data and test results. Coefficients of equivalence were derived to indicate the overall relationship between WJ-R reading performance for computer and traditional administrations, as well as specific relationships for each form of the WJ-R. Additional correlation coefficients were calculated to investigate relationships between background variables and CARS scores to changes in WJ$\mathrm{R}$ performance between computer and traditional administrations.

\section{RESULTS}

Summary statistics for background variables are presented in Table 1. The mean age (9.4 years) and median grade (3.7) shown in the table indicate a younger sample than computer reading studies have generally examined. Data for sex, race, and referral reason are all typical of the population served by the center. Mean scores from the Conners Teacher Rating Scale, special education and retention rates, and primary diagnosis are consistent with previous studies of the center's referred population (e.g., Evans \& Devers, 1993), reflecting students with many symptoms, but either no primary diagnosis or more than one diagnosis. The average IQ of the sample falls in the average-to-low-average range, the range characteristic of students with learning disabilities (Sattler, 1988). However, WJ-R means (based on traditional administration) fall in the same range, inconsistent with the below-average achievement of students with learning disabilities. Mean CARS scores show a tendency to report enjoyment of computers, with mild-to-moderate levels of anxiety.

Table 2 shows the results of the primary analysis. Scores from computer administration correlated highly with those for traditional administration across tests and administration order, with overall equivalence coefficients of $r=.91$ for Letter-Word Identification Tests and of $r=.86$ for Word Attack Tests. These high coefficients negated the search for variables explaining differences between the methods of administration; neither the background variables, the IQ, nor the CARS scores correlated significantly with changes in either test's standard scores 
Table 1

Subject Characteristics and Assessment Results

\begin{tabular}{|c|c|c|c|c|}
\hline Variable & Mean & Median & Mode & Range \\
\hline Age (years) & 9.2 & & & $5.7-16.0$ \\
\hline Grade & & 3.7 & & K. $1-10.6$ \\
\hline Sex & & & Males $(64.7 \%)$ & \\
\hline Race & & & Caucasian $(68.6 \%)$ & \\
\hline Primary referral reason* & & & Educational (58\%) & \\
\hline Primary diagnosis & & & None $(27 \%)$ & \\
\hline Socioeconomic status (SES) $\dagger$ & 31.8 & & & $11-61$ \\
\hline \multicolumn{5}{|l|}{ Conners teacher rating scale- 28} \\
\hline Conduct problems & 62.9 & & & $43-98$ \\
\hline Hyperactivity & 64.5 & & & $42-99$ \\
\hline Inattention-Passivity & 65.1 & & & $43-86$ \\
\hline Special Education & & & None $(90.2 \%)$ & \\
\hline Grade Retention & & & None $(68.6 \%)$ & \\
\hline Intelligence Quotient (IQ) & 92.8 & & & $58-120$ \\
\hline \multicolumn{5}{|l|}{ WJ-R Tests of Achievement +} \\
\hline Letter-Word Identification & 93.3 & & & $47-147$ \\
\hline Word Attack & 94.3 & & & $59-153$ \\
\hline \multicolumn{5}{|l|}{ Computer Anxiety Rating Scale§ } \\
\hline Anxiety scale & 16.5 & & & $10-35$ \\
\hline Liking scale & 32.0 & & & $20-40$ \\
\hline
\end{tabular}

*Primary referral and diagnosis categories included medical, educational, other, combination, and none. 'Average SES scores range from 30 to 39 points. ‡Means are based on administration of the WJ-R using the traditional method. §Computer Anxiety Rating Scale scores can range from 0 (low) to 40 (high).

from one method of administration to the other. Moreover, if a student's Letter-Word-Identification performance was better for one administration method, it did not correspond with better Word-Attack performance for the same administration method $(r=.26, p>.05)$.

\section{DISCUSSION}

This study compared student reading scores from two WJ-R reading tests using traditional and computer administration methods. Assessing the relative magnitude of the obtained coefficients of equivalence is difficult. The equivalence of WJ-R Form A with Form B would provide a reference point as an upper limit for the coefficients obtained in the present study, yet these values are not reported in the WJ-R technical manual. Coefficients of equivalence for other psychoeducational tests may be helpful. The Test of Nonverbal Intelligence (TONI; Brown, Sherbenou, \& Johnsen, 1982) reports equivalence coef- ficients ranging approximately from .70 to .89 for school-age children given its two forms. These data are interpreted as indicating the equivalence of the forms. The second edition of the TONI (Brown, Sherbenou, \& Johnsen, 1990) found slightly higher coefficients, with an overall coefficient of .86. The Peabody Picture Vocabulary Test-Revised (Dunn \& Dunn, 1981) reports an average equivalence coefficient of .79 across the age range of its alternate forms. The coefficient is similar to reported equivalence coefficients from intelligence tests having more than one form. The present study's equivalence coefficients thus appear to be of the magnitude of coefficients for psychoeducational measures with alternate forms, although few measures have more than a single form. The magnitude of the equivalence coefficients also provides evidence that reading level may be similar for computer and page displays.

It would be misleading to conclude that the present study's high coefficients of equivalence indicate that the

Table 2

Mean Reading Scores Across Administration Methods

\begin{tabular}{lccc}
\hline \multicolumn{3}{c}{ Mean Reading Scores Across Administration Methods } \\
\cline { 2 - 4 } & \multicolumn{3}{c}{ Administration Method } \\
\cline { 2 - 4 } & Traditional & Computer & $r$ \\
\hline Letter-Word Identification & 96.8 & 95.4 & $.94^{*}$ \\
$\quad$ Form A trad. vs. Form B comp. & 89.2 & 92.0 & $.88^{*}$ \\
Form B trad. vs. Form A comp. & 93.3 & 93.9 & $.91^{*}$ \\
Forms A \& B trad. vs. forms A \& B comp. & & & \\
Word Attack & 96.9 & 97.1 & $.85^{*}$ \\
$\quad$ Form A trad. vs. Form B comp. & 91.3 & 93.0 & $.87^{*}$ \\
Form B trad. vs. Form A comp. & 94.3 & 95.2 & $.86^{*}$ \\
Forms A \& B trad. vs. Forms A \& B comp. & & & \\
\hline Note-trad., traditional; comp., computer. ${ }^{*} p<.001$. & &
\end{tabular}


computer and page displays of WJ-R items are equivalent, and that computer display can be readily substituted for the traditional page method. The term coefficient of equivalence directly implies an equivalence of the domain being assessed, and only indirectly implies an equivalence of tests. Thus, high equivalence coefficients for any computerized form of an existing test would not automatically eliminate the need for a separate standardization. As such, the present study appears to support the ability of computers to measure traditionally assessed reading domains, and not the absolute equivalence of computer and traditional WJ-R administrative methods.

As more everyday information is displayed on computers, comprehensive assessment of student reading skills may need to include skills for reading from computer displays. This may create a problem for many practitioners, as too often practitioners rely on a single readingachievement score from a single reading measure, and avoid having to resolve differences between several reading scores from different measures. If more than one measure is given, one score is often chosen as representative of the student's skills, and the other score(s) are ignored. In order to avoid ignoring information, practitioners can combine reading scores into a single composite score. With adequate internal-consistency reliability and correlation between scores, composite scores can produce a more reliable score that is nearer the student's true score (Dunteman, 1984; Mosier, 1943). Because the equations that yield the composite standard score and reliability are too complex to perform reliably by hand, an ideal role of computer-administered reading tests may be to measure computer reading skills as one component of a student's overall reading skills, and then to combine the score(s) from computer assessment with scores from traditional page display to form a reading composite score.

Aspects other than reading accuracy require investigation in order to compare children's reading skills on the computer monitor with those on the printed page. For example, previous studies showing poorer comprehension with computer text may result from differences in reading rate, type of errors made (omissions, substitutions, insertions, repetitions, etc.), retention, and application. The physiology of reading may also differ, especially as monitors are often read from a more horizontal position than are books. The resulting eye fixations, head movements, and fatigue rates may differ. Computerpresented text may play an increasingly important role in children's futures. With further study, it may be possible to enhance computer displays in such a way that deficiencies are minimized and applications such as psychoeducational, pediatric, and psychological assessment become more practical.

\section{REFERENCES}

Brown, L., Sherbenou, R. J., \& Johnsen, S. K. (1982). Test of nonverbal intelligence. Austin, TX: Pro-Ed.

Brown, L., Sherbenou, R. J., \& Johnsen, S. K. (1990). Test of nonverbal intelligence (2nd ed.). Austin, TX: Pro-Ed.

Dunn, L. M., \& DunN, L. M. (1981). Peabody picture vocabulary testrevised. Circle Pines, MN: American Guidance.

Dunteman, G. H. (1984). Introduction to multivariate analysis. Beverly Hills, CA: Sage.

Evans, L. D. (1993). Sight word inventory for teaching and testing. North Little Rock, AR: WtL Publishing.

EVANS, L. D., \& Devers, R. J. (1993). Severe discrepancy determination for retained and nonretained students: Age-based or gradebased achievement scores? Journal of Psychoeducational Assessment, 11, 20-28.

FARRELL, A. D. (1991). Computers and behavioral assessment: Current applications, future possibilities, and obstacles to routine use. $B e$ havioral Assessment, 13, 159-179.

Gambrell, L. B., Bradley, V. N., \& McLaughlin, E. M. (1987). Young children's comprehension and recall of computer screen displayed text. Journal of Research in Reading, 10, 156-163.

Gould, J. D., Alfaro, L., Barnes, V., \& FinN, R. (1987). Reading is slower from CRT displays than from paper: Attempts to isolate a single-variable explanation. Human Factors, 29, 269-299.

Gould, J. D., \& GRISCHKOWSKY, N. (1984). Doing the same work with hard copy and with CRT terminals. Human Factors, 26, 323-337.

HAas, C., \& HAYES, J. R. (1986). What did I just say? Reading problems in writing with the machine. Research in the Teaching of English, 20, 22-35.

KINZER, C. K., SHERwoOd, R. D., \& LoOFBourRow, M. G. (1989). Simulation software vs. expository text: A comparison of retention across two instructional tools. Reading Research \& Instruction, 28, 41-49.

LOYD, B. H., \& GRESSARD, C. P. (1984). Reliability and factorial validity of computer attitude scales. Educational \& Psychological Measurement, 44, 501-505.

MiLls, C. B., \& Weldon, L. J. (1987). Reading text from computer screens. ACM Computing Surveys, 19, 329-358.

Mosier, C. I. (1943). On the reliability of a weighted composite. Psychometrika, 8, 161-168.

Muter, P., \& MAURUTto, P. (1991). Reading and skimming from computer screens and books: The paperless office revisited? Behaviour \& Information Technology, 10, 257-266.

SATTLER, J. M. (1988). Assessment of children (3rd ed.). San Diego, CA: Author.

ScHAUDT, B. A. (1987). The use of computers in a direct instruction reading lesson. Reading Psychology, 8, 169-178.

TORGESEN, J. K. (1986). Using computers to help learning disabled children practice reading: A research-based perspective. Learning Disabilities Focus, 1, 72-81.

WEPNER, S. B. (1987). Connecting computers and reading disabilities. Journal of Reading, Writing, \& Learning Disabilities International, 3, 297-307.

WooDCock, R. W., \& Johnson, M. B. (1989, 1990). Woodcock-Johnson Pychoeducational Battery-Revised. Allen, TX: DLM Teaching Resources.

Wright, P., \& Lickorish, A. (1983). Proof-reading texts on screen and paper. Behavior \& Information Technology, 2, 227-235.

Yokley, J. M., Coleman, D. J., \& Yates, B. T. (1990). Cost effectiveness of three child mental health assessment methods: Computerassisted assessment is effective and inexpensive. Journal of Mental Health Administration, 17, 99-107.

(Manuscript received November 14, 1994; revision accepted for publication December 27, 1994.) 